\title{
Behavioural patterns of free roaming wild boar in a spatiotemporal context
}

\author{
Dana Erdtmann ${ }^{\text {Equal first author, } 1}$, Oliver Keuling ${ }^{\text {Corresp. Equal first author, } 1}$ \\ ${ }^{1}$ Institute for Terrestrial and Aquatic Wildlife Research, University of Veterinary Medicine Hannover, Hannover, Germany \\ Corresponding Author: Oliver Keuling \\ Email address: oliver.keuling@tiho-hannover.de
}

Although the almost worldwide distributed wild boar Sus scrofa is a well-studied species, little is known about the behaviour of autochthonous, free living wild boar in a spatiotemporal context which can help to better understand wild boar in conflict terms with humans and to find solutions. The use of camera traps is a favourable and noninvasive method to study them. To observe natural behaviour, 60 camera traps were placed for three months in a state forest of $17.8 \mathrm{~km}^{2}$ in the region of the Luneburg Heath in northern Germany. In this area wild boar, roe deer, red deer, wolves and humans are common. The cameras recorded $20 \mathrm{~s}$ length video clips when animals passed the detection zone and could be triggered again immediately afterwards. In total 38 distinct behavioural elements were observed, which were assigned to one of seven behavioural categories. The occurrence of the behavioural categories per day was evaluated to compare their frequencies and see which are more essential than others. Generalised Additive Models were used to analyse the occurrence of each behaviour in relation to habitat and activity time. The results show that essential behavioural categories like foraging behaviour, locomotion and vigilance behaviour occurred more frequently than behaviour that "just" served for the well-being of wild boar. These three behavioural categories could be observed together mostly in the night in broad-leaved forests with a herb layer of 50-100 $\%$, comfort behaviour occurred mostly at the ponds in coniferous forest. It is also observable that the behavioural categories foraging and comfort behaviour alternated several times during the night which offers the hypothesis that foraging is mostly followed by comfort behaviour. These findings pave the way towards implementing effective control strategies in the wild and animal welfare in captivity. 


\section{Behavioural patterns of free roaming wild boar in a}

\section{2 spatiotemporal context}

3

4

5 Dana Erdtmann, Oliver Keuling*

6

7 Institute for Terrestrial and Aquatic Wildlife Research, University of Veterinary Medicine

8 Hannover, Bischofsholer Damm 15, 30173 Hannover, Germany.

9

$10 *$ Corresponding author

11

12 E-Mail: dana.erdtmann@gmx.de, oliver.keuling@tiho-hannover.de 


\section{Abstract}

14 Although the almost worldwide distributed wild boar Sus scrofa is a well-studied species, little is

15 known about the behaviour of autochthonous, free living wild boar in a spatiotemporal context which can help to better understand wild boar in conflict terms with humans and to find solutions. The use of camera traps is a favourable and non-invasive method to study them. To observe natural behaviour, 60 camera traps were placed for three months in a state forest of $17.8 \mathrm{~km}^{2}$ in the region of the Luneburg Heath in northern Germany. In this area wild boar, roe deer, red deer, wolves and humans are common. The cameras recorded $20 \mathrm{~s}$ length video clips when animals passed the detection zone and could be triggered again immediately afterwards. In total 38 distinct behavioural elements were observed, which were assigned to one of seven behavioural categories. The occurrence of the behavioural categories per day was evaluated to compare their frequencies and see which are more essential than others. Generalised Additive Models were used to analyse the occurrence of each behaviour in relation to habitat and activity time. The results show that essential behavioural categories like foraging behaviour, locomotion and vigilance behaviour occurred more frequently than behaviour that "just" served for the wellbeing of wild boar. These three behavioural categories could be observed together mostly in the night in broad-leaved forests with a herb layer of 50-100\%, comfort behaviour occurred mostly at the ponds in coniferous forest. It is also observable that the behavioural categories foraging and comfort behaviour alternated several times during the night which offers the hypothesis that

32 foraging is mostly followed by comfort behaviour. These findings pave the way towards implementing effective control strategies in the wild and animal welfare in captivity. 


\section{Introduction}

35 Animals behave in order to survive and reproduce themselves (Naguib 2006; Kappeler 2009) and

36 choose different habitats to increase their survival and fitness. Behaviour is defined as control

37 and exercise of movements or signals with which an animal interacts with conspecifics or other components of its animate and inanimate environment, as well as activities which serves for the homoeostasis of an individual (Kappeler 2009). Some animals within a given population, however, will perform much better in some habitats than in others (Gaillard et al. 2010). Within a day terrestrial herbivores relocate between foraging areas, drinking and resting sites and places used for other activities at different times of the day (Owen-Smith et al. 2010). Predation pressure, inter- and intraspecific competition, diseases and human disturbances can affect the behaviour and consequently the survival and fitness of animals (Gaillard et al. 2010). A first step to assess functions of a specific behaviour, and henceforth to analyse behaviour changes, is to watch the behavioural elements performed in specific places at defined times of the day to understand their benefits for survival.

Among the terrestrial even-toed ungulates (Artiodactyla) the Suina (Price et al. 2005; Gatesy 2009) is the only omnivorous non-ruminant suborder with several of original features (Briedermann 2009). Among the Suina the species Sus scrofa is distributed almost worldwide (Lowe et al. 2000; Briedermann 2009; Mayer 2009). Wild boar are amongst the most intelligent and adaptable large terrestrial mammals in Central Europe (Briedermann 2009) making it very interesting for behavioural analyses in relation to the time of day and different habitat types. Only few studies analysed the behaviour of wild boar under natural conditions (Allwin et al.

55 2016; Probst et al. 2017). Most studies were conducted at artificial feeding places (Schneider 1980; Saebel 2007; Focardi et al. 2015) or in enclosures (e.g. Gundlach 1968; Beuerle 1975; 
57 Altmann 1989) which does not necessarily enable to cover all behavioural elements that would

58 normally occur over the course of a day in a wild population. There is a lack of recent field

59 studies under natural conditions due to the fact that wild boar are widely seen as a pest because

60 of their constant conflict terms with humans, such as crop damage, disease transmission (Keuling

61 et al. 2013; Allwin et al. 2016; Probst et al. 2017) and zoonosis, road traffic accidents, and

62 disturbances to sensitive plant communities (Maselli et al. 2014). Though, it is very important to

63 understand the behaviour of wild boar to be able to implement effective management strategies

64 for reduction plans (Maselli et al. 2014) as well as for animal welfare in enclosures (Kovács et al.

65 2017).

66 As the behaviour of wild boar hardly differs from that of domestic pigs (Stolba and Wood-Gush

67 1989; GÖT and BAT 2003; Mayer 2009), their behaviour can be summarised by: resting,

68 locomotion, behaviour caused by metabolism (ingestion and excretion), comfort, vigilance,

69 social and sexual (Gundlach 1968; Beuerle 1975; Saebel 2007) (see Table 1). Most of the day

$70(70-90 \%)$ is spend on foraging to fulfil the animal's basic needs (Briedermann 1971; GÖT and

BAT 2003; Keuling and Stier 2009), of which about half is filled by ingestion or locomotion

72 (Stolba and Wood-Gush 1989; Morelle et al. 2014). Comfort behaviour, in contrast, is practised

much less but serves the important function of well-being (Keuling and Stier 2009).

74 Wild boar, however, due to their intelligence and adaptability, can learn new attitudes due to

75 training and imitation (Schneider 1980; Broom et al. 2009; Sommer et al. 2016). Studies show

76 that the behaviour of wild boar differs depending on the region (habitat), population, and

77 individual (Schneider 1980). For activity and habitat choice behaviour in particular, the same

78 biotic and abiotic factors are important (Choquenot et al. 1996; Lemel et al. 2003; Briedermann

79 2009). In general, wild boar prefer broad-leaved forest with older mast species (beech, oak) 
80 while foraging (Berger 2006; Bertolotto 2010) which they mainly explore in the first half of their 81 activity time (Keuling and Stier 2009). In contrast, coniferous forest is preferred for their resting 82 sites (Bertolotto 2010) as well as secure places for wallowing and sleeping (GÖT and BAT 2003;

83 Keuling and Stier 2009; Allwin et al. 2016). Comfort behaviour often takes place in the second 84 half of the night (Keuling and Stier 2009).

To pave the way of authentic wild boar behaviour in a spatiotemporal context, we aimed to 1)

87

\section{Materials and Methods}

\section{Study area}

98 The study area "Süsing" was a $17.8 \mathrm{~km}^{2}$ state forest located in the Luneburg Heath in Germany. The region is characterised by large-area coniferous forest (Pinus sylvestris, Picea abies, Larix decidua \& L. kaempferi, Pseudotsuga menziesii) and small-area oak (Quercus robur) and beech (Fagus sylvatica) forests (Keuling et al. 2013). The mean annual temperature is $8{ }^{\circ} \mathrm{C}$ and the 
103 wild boar (about 8 animals $/ \mathrm{km}^{2}$ during the study period, calculated according to Rowcliffe via

104 Random Encounter Model (REM) (Rowcliffe et al. 2008)), there are also high numbers of roe

105 (Capreolus capreolus) and red deer (Cervus elaphus), as well as a few wolves (Canis lupus).

106

\section{Data collection}

108

109

110

111

112

113

114

115

116

117

118

119

120

121

122

123

124

125

Direct observations (compared to radio telemetry) are required to record the behaviour of animals and consequently also get information on activity and habitat choices (Cagnacci et al. 2010). One cost-efficient method for the observation of free roaming wild boar is the use of camera traps. The advantage of camera traps is that they are non-invasive (Rovero et al. 2010; Rowcliffe et al. 2011), and as a consequence, ideal to study nocturnal and crepuscular animals which avoid humans (Rovero et al. 2010). The technique is applicable to the study of wild boar given they rarely react to camera traps (Amelin 2014). Using ESRI ${ }^{\circledR}$ ArcGis 10.1, 50 random points (Rowcliffe et al. 2008; Rovero et al. 2013) separated by a minimum distance of $100 \mathrm{~m}$ (Passon et al. 2012; Hofmeester et al. 2017) were determined and afterwards explored with GPS (Rovero et al. 2010; Rowcliffe et al. 2011). Additionally ten places with a high probability of wild boar occurrence (e.g. wallows, fresh rooting places, salt lick) were selected to reveal all behavioural elements necessitated for the ethogram. Cameras were placed at all 60 places and had an effective detection distance of 8-20 m. Animal's behaviours were able to be defined in distances up to $20-30 \mathrm{~m}$ in front of the cameras.

The set-up of the Bushnell ${ }^{\circledR}$ TROPHY CAM ${ }^{\mathrm{TM}}$ and Bushnell ${ }^{\circledR}$ TROPHY CAM HD ${ }^{\mathrm{TM}}$ camera traps took place on 03.03 .2014 . The 50 cameras used for statistically evaluable behaviour observations were hung as near as possible to the random points, at trees in $90 \mathrm{~cm}$ height, orientated parallel to the ground (Rowcliffe et al. 2011; Meek et al. 2012) to capture some open 
126 space on the video clips, and if possible, a deer crossing which comes to or goes away from the

127 camera (Bengsen et al. 2011; Rowcliffe et al. 2011). The additional ten camera traps, which are

128 statistically irrelevant for the behaviour frequency, were hung at different heights (most of the

129 time higher than $90 \mathrm{~cm}$ and with an angle $<90^{\circ}$ to the ground) depending on the area to capture a

130 large field of view and thus a lot of behaviours. To not disturb the natural behaviour of the

131 animals, no bait or lure were used at the random points (Rowcliffe et al. 2011; Meek et al. 2012).

132 Each camera had a passive infrared sensor (PIR) and recorded, day and night, a 20 s video clip

133 without sound when they were triggered. $1 \mathrm{~s}$ after the ending of the latest video the camera traps

134 could be triggered again (Rovero et al. 2010; Rowcliffe et al. 2011). The video clips were stored

135 on SD cards, which were changed biweekly. Function of cameras and battery levels were

136 checked during change of SD cards. After about three months, on 04.06.2014, the camera traps

137 were retrieved.

138 The date and time for each clip was recorded (the time is presented in segments as full hours 139 with the following full hour, e.g. 00:00 o'clock =00:00:00 - 00:59:59 o'clock).

140 The habitat was described at each of the camera locations. First, every place was assigned to one

141 of the six types: track, forest aisle, pond (incl. wallows), field edge (simultaneously edge of the

142 forest), salt lick or wooded. After that, within a radius of $10 \mathrm{~m}$ the tree and shrub layer were

143 described with main species (no trees/shrubs, broad-leaved, mixed or coniferous forest) and 144 cover $(0 \%, 0-50 \%$ or $50-100 \%)$. The herb layer was also divided as described. Here the main 145 species were no herbs, common bracken (P.a. = Pteridium aquilinum), European blueberry (V.m. 146 = Vaccinium myrtillus), bracken and blueberry (P.a.\&V.m.) or herbs (e.g. Rubus sectio Rubus,

147 Urtica dioica, Poaceae, a few Cyperaceae and Polypodiopsida). In addition, the cover of 148 deadwood $(0 \%, 0-25 \%$ or $25-50 \%)$ was registered. 
149 In this study the sampling method "behaviour sampling" and the recording method "time 150 sampling, one-zero sampling” (Altmann 1974; Geissmann 2002) were used. That means, during 151 a sampling interval (video length of $20 \mathrm{~s}$ ) all visible boar were observed as one group and it was 152 noted for every behavioural element if it occurred in the video clip or not. An ethogram was 153 created following literature review (e.g. Gundlach 1968; Saebel 2007; Briedermann 2009) and 154 own observations, at which exclusively the own observations are shown in Table 1.

\section{Data analysis}

157 Wild boar could be identified on 1,227 of ca. 8,500 video clips as well as at 57 of 60 places. 158 From 1,169 video clips, a behavioural context could be analysed (645 of 673 video clips at the random points, 524 of 554 video clips at the other ten places), but only the video clips at the random points were statistically analysed, because the other ten did not fulfil the statistical requirements (not randomly, hung at different heights).

To compare the occurrence per day of the seven different behavioural categories at the random points, two analyses were done: First, to calculate the percentage of each behavioural category, the number of observations per behavioural element (BE) and random point (RP) at one day was calculated as the function:

166

$$
N_{\mathrm{obs}, \mathrm{d}=1}(B E, R P)=\frac{N_{\mathrm{obs}}(B E, R P)}{d_{R P}}
$$

where $\mathrm{N}_{\mathrm{obs}}(\mathrm{BE}, \mathrm{RP})$ is the total number of observations per behavioural element and random point and $d_{R P}$ is the number of trial days per random point. Then the mean number of observations per behavioural element at one day could be calculated by:

$$
\bar{x}(B E)=\frac{\sum\left(N_{o b s, d=1}(B E, R P)\right)}{50}
$$


171 where 50 is the number of random points. The percentage for each behavioural category (BC) in

$172 \%\left(\right.$ with $\left.\sum(\mathrm{P}(\mathrm{BC}))=1\right)$ was then calculated by:

$$
P(B C)=\frac{\sum_{(B C)}(\bar{x}(B E)) * 100}{\sum(\bar{x}(B E))}
$$

174 where $\sum_{(\mathrm{BC})}(\bar{x}(\mathrm{BE}))$ describes the sum of the mean numbers of observations per behavioural 175 element over all behavioural elements which belong to one behavioural category, and $\sum(\bar{x}(\mathrm{BE}))$ 176 describes the sum of the mean numbers of observations per behavioural element over all 177 behavioural elements.

178 Second, to compare the occurrence of the behavioural categories, the number of observations per 179 behavioural category and random point was calculated as the function:

$$
N_{o b s}(B C, R P)=\sum_{(B C, R P)}\left(N_{\mathrm{obs}, \mathrm{d}=1}(B E, R P)\right)
$$

where $\sum_{(\mathrm{BC}, \mathrm{RP})}\left(\mathrm{N}_{\mathrm{obs}, \mathrm{d}=1}(\mathrm{BE}, \mathrm{RP})\right)$ describes the sum of the numbers of observations per behavioural element and random point at one day over all behavioural elements, which belong to one behavioural category. Afterwards pairwise comparisons of means (over all random habitats, $\mathrm{N}=300$ ) were conducted with $\mathrm{R}$ software version 3.1.1 (R Core Team 2014), using the packages "nlme" (Pinheiro and Bates 2014) and "multcomp" (Hothorn et al. 2014). Therefore, the linear mixed model (LMM) (Dormann and Kühn 2009) combined with the post hoc analysis least

187 squares means (LSMEAN) (SAS Institute Inc. 2011) with Tukey adjustment (NIST/SEMATECH 2013) was performed.

189 For the analyses of the behaviour in a spatiotemporal context, similar behavioural elements were 190 grouped as listed: locomotion; sniffing and winding; defecating and urinating; vigilance 191 behaviour; rooting and pawing; salt ingestion; sucking attempt and suckling; chewing and 192 feeding (attempt); drinking; wallowing, nibbling and stretching; shaking; rubbing; scratching 193 (one's bottom) and rolling; social interactions; sexual behaviour (see Table 1). For each 
194 grouping, the number of video clips per time of day was summed over all 60 camera locations

195 with Microsoft ${ }^{\circledR}$ Excel 2007 to determine the activity maxima in general. Significant habitat

196 preferences per behaviour were derived from a generalised additive model (GAM) dependent on

197 the time of day and habitat type. Using the data from the random camera locations, it was

198 calculated with R software version 3.1.1 (R Core Team 2014), using the "mgcv" package (Wood

199 2014), for each behaviour with greater than 20 observations. For the same data, tests for spatial

200 dependence of residuals were conducted on a sample of 1000 observations. We calculated

201 Moran's I for the first lag with R software version 4.0.2 (R Core Team 2020), using the "ncf"

202 package (Bjornstad and Cai 2020). We did not find significant spatial autocorrelation. Since it is

203 not possible to monitor the whole study area completely and consequently every possible habitat

204 type, we can just draw conclusions out of the results given by random placed camera traps.

205

206

\section{Results}

208

209

210

211

212

213

214

215

216

Comparing the proportion of the six observed behavioural categories at the 50 random points, locomotion accounts for more than half of the observations (52\%). This behaviour occurred significantly more often than all other behavioural categories (Fig. 1, LMM \& LSMEAN see Table 2). It was followed by olfactory $(22.02 \%)$, vigilance $(13.33 \%)$ and foraging behaviour $(8.81 \%)$. The olfactory behaviour occurred significantly more often than foraging behaviour and comfort behaviour as well as social interactions. Vigilance behaviour occurred significantly more often than comfort behaviour and social interactions. Comfort behaviour $(1.99 \%)$ and social interactions $(1.85 \%)$ were rarely observed. There were no significant differences between all other pairwise comparisons. 
218 The ten non-random cameras were additionally used for general descriptions of behavioural

219 elements that only occurred there: salt ingestion, feeding attempt, getting frightened, stretching,

220 nibbling, wallowing, chasing away, snout knock, and copulation attempt. The observed wild boar

221 are crepuscular and nocturnal because their main activity was between 17:00 and 08:59 o'clock.

222 The activity maxima of locomotion occurred in the hour of 22:00 o'clock and in the hour of 223 03:00 o'clock. During this time the wild boar significantly avoided tracks and significantly 224 preferred forest aisles, ponds and broad-leaved forest with 50-100\% herbs and 25-50\% 225 deadwood (GAMs see S1 Appendix).

226 The highest activity maximum of sniffing and winding (olfactory behaviour) was between 20:00 227 and 21:59 o'clock and a secondary maximum in the hour of 03:00 o'clock. During this time the 228 wild boar significantly avoided tracks and habitats with a shrub layer out of coniferous forest 229 (GAMs see S1 Appendix). Ponds and habitats with 50-100 \% herbs and 25-50 \% deadwood were 230 significantly preferred. Data show no obvious tendency for defecating and urinating.

231 The vigilance behaviour had an activity maximum at 22:00 o'clock and a secondary maximum at 232 03:00 o'clock. During this time wild boar significantly preferred forest aisles, ponds, a tree layer 233 out of broad-leaved and mixed forest, a shrub layer out of broad-leaved forest, a herb layer with 234 a cover of 50-100\% and 25-50\% deadwood (GAMs see S1 Appendix).

235 The foraging behaviour had an activity maximum at 17:00 o'clock for salt ingestion, which only 236 occurred at the salt lick, and for chewing and feeding (attempt), which occurred significantly 237 more often at ponds and places with a shrub cover of 50-100 \% and blueberries (GAMs see S1 238 Appendix). At 19:00 o'clock, there was a secondary maximum again for chewing and feeding 239 (attempt). In the hour of 21:00 o'clock a maximum of salt ingestion and for water intake (only at 
240 ponds) was observed. Another maximum occurred at 22:00 o'clock for sucking attempt and

241 suckling, which mostly occurred at the ponds and at the salt lick, and for rooting and pawing.

242 Pawing could significantly be observed at forest aisles, ponds and broad-leaved forest with herbs

243 (GAMs see S1 Appendix). At 03:00 o'clock there was another maximum for rooting and pawing

244 and in the hour of 04:00 and 06:00 o'clock again two low secondary maxima for chewing and

245 feeding (attempt).

246 The comfort behaviour showed a secondary maximum for shaking in the hour of 17:00 o'clock

247 at the salt lick. Furthermore, at around 20:00 o'clock there was a maximum for all elements of

248 comfort behaviour, e.g. for shaking, which mostly occurred at the ponds this time. Another

249 secondary maximum was in the hour of 23:00 o'clock for wallowing, mostly followed by

250 rubbing, nibbling and stretching, which occurred only at the ponds. In the hour of 00:00 o'clock

251 there was a secondary maximum for scratching (one's bottom) and rolling, in which scratching

252 often occurred at the ponds while rubbing.

253 The social interactions had a low maximum (compared to the size of the maxima of the other

254 behavioural categories) in the hour of 20:00 o'clock. In general, this behavioural category 255 occurred more often in the first half of the night with preferred habitats of forest aisles, ponds, a 256 shrub layer out of 0-50\% broad-leaved and mixed forest, herbs and 25-50\% deadwood (GAMs

257 see S1 Appendix). The sexual behaviour only occurred once at the salt lick in the hour of 20:00 258 o'clock.

259 For the several activity maxima per behavioural category in total, the olfactory behaviour 260 occurred mostly in the hour of 20:00 o'clock in form of winding at a rubbing tree during comfort 261 behaviour, in the hour of 21:00 o'clock in form of winding at the salt lick during salt ingestion 262 and in the hour of 03:00 o'clock in form of sniffing on the ground during rooting (Fig. 2). 
263 Furthermore, foraging behaviour and comfort behaviour alternated during the night. After

264 awakening, wild boar first attended to foraging behaviour between 17:00 and 19:59 o'clock,

265 followed by a short maximum of comfort behaviour in the hour of 20:00 o'clock. Afterwards,

266 between 21:00 and 22:59 o'clock, the animals again attended to foraging behaviour until a longer

267 period of comfort behaviour can be observed between 23:00 and 01:59 o'clock. To a minor

268 degree, the rest of the night (02:00-08:59 o'clock) is used for foraging behaviour.

269

270

\section{Discussion}

272 During the observation of wild boar with camera traps, 38 behavioural elements were observed 273 in this study which could be combined into seven behavioural categories. The behavioural 274 category locomotion occurred the most in this study, followed by olfactory, vigilance and 275 foraging behaviour. In many other studies (e.g. Stolba and Wood-Gush 1989; GÖT and BAT 276 2003; Saebel 2007) foraging behaviour was the most observed behavioural category. A reason

277 for this might be that in these studies locomotion was always analysed in its pure form and not 278 when it occurred together with other behavioural categories like foraging behaviour 279 (Briedermann 1971). Another reason might be that in our study the duration of the different 280 behavioural categories were not measured and it could be that camera traps are biased towards 281 faster movements (Rowcliffe et al. 2016) like running. However, fast locomotion (i.e. running 282 and flight) accounts for only $22.27 \%$ of the locomotion in total and $11.58 \%$ of all observations. 283 In addition, wild boar never move fast for longer time spans (Briedermann 2009; Morelle et al. 284 2014; Keuling et al. 2018), therefore, fast locomotion will not have strong influence on the 285 results. On the other hand, slow behaviours such as foraging take longer and might therefore 
286 result in multiple videos captured by the same camera trap. It is also possible that other studies

287 counted sniffing for food as foraging behaviour, which was also often seen in this study. It is

288 important to note, however, that related studies focused on domestic pigs (e.g. Stolba and Wood-

289 Gush 1989; GÖT and BAT 2003; Mayer 2009), wild boar living in enclosures (e.g. Gundlach

290 1968; Beuerle 1975; Altmann 1989) or observed at feeding places (e.g. Schneider 1980; Saebel

291 2007; Focardi et al. 2015) and hence might show difference to behaviour in the wild.

292 Furthermore, we observed only one wild boar population and our study period amounted just a

293 quarter year and does not reflect the average for an entire year. Wild boar in this study spent

294 more time to foraging then undertaking comfort-related behaviour. According to other studies

295 personal hygiene contributes less to the basic need of wild boar compared to foraging, because

296 the latter serves to ensure survival and personal hygiene "just" for well-being (Saebel 2007;

297 Keuling and Stier 2009). Consequently, our results and that from other studies confirm the

298 hypothesis that behavioural categories, which are essential for survival like locomotion, 299 vigilance and foraging behaviour, occur more often than categories serving for the well-being. 300 Since olfactory behaviour occurred together with essential behaviour and those serving for the 301 well-being it is not clearly assigned to one of them.

302

303

\section{Behaviour in a spatiotemporal context}

304

305

306

307

308

The maxima of locomotion and vigilance behaviour were observed with foraging behaviour (Fig.

2). Wild boar have to travel long distances while foraging and often have to cross open and unsecure spaces (Meynhardt 1982; Cahill et al. 2003), hence vigilance behaviour to avoid predators is important. Meanwhile the observed wild boar mostly used forest aisles or stayed in broad-leaved forests with a herb layer of 50-100 \%. In other studies it was found that wild boar 
309 preferred broad-leaved forest for foraging (Berger 2006; Bertolotto 2010). Wild boar move fast

310 and take the shortest path when crossing an open unsecure space (Meynhardt 1982). Manmade

311 forest aisles that are rarely used by humans are probably used by wild boar (Allwin et al. 2016)

312 to allow fast movement through forest areas. Thus, the hypothesis that foraging and related

313 behaviour occur in broad-leaved forest is confirmed.

314 Social interactions and the only observation of sexual behaviour occurred during the maximum

315 of comfort behaviour. This may be because comfort behaviour (Saebel 2007) and social

316 interactions could be observed mostly at the ponds (containing wallows) where the animals feel

317 safe (Keuling and Stier 2009). In addition, all ponds were located in coniferous forest, and wild

318 boar prefer pine trees for rubbing (Mayer 2009). Furthermore, these three behavioural categories

319 could be observed many times at the saltlick. In general, however, nearly all of the seven

320 behavioural categories could be observed at the ponds. Consequently, the hypothesis that

321 comfort and related behaviour occur in coniferous forest and at places where the wild boar feel

322 safe cannot be rejected.

323 If we compare the alternation of foraging and comfort behaviour during the night with the results

324 of another study (Gundlach 1968), the observations of the other study lack the first period of

325 foraging behaviour after awakening and they also refer to diurnal wild boar. Our data support the

326 results of other studies (Saebel 2007; Keuling and Stier 2009) which found that wild boar mostly

327 attend to foraging behaviour in the first half of the night while a higher occurrence of comfort

328 behaviour during the second half of the night is not obvious. It rather gives the impression that

329 foraging is always followed by comfort behaviour. Consequently, comfort behaviour occurs later 330 in the night than foraging behaviour. 


\section{Functions of the behavioural elements}

333 The behaviour of an animal essentially contributes to its survival and reproductive success

334 (Naguib 2006; Kappeler 2009). If we generalise the ecological model for the locomotion of wild

335 boar (Morelle et al. 2014), it appears that the behaviour of wild boar is a result of the interaction

336 of intrinsic (energy gain, escape from predators and/or conspecifics, reproductive success) and

337 extrinsic (habitat, climate, presence of predators) factors - and thus, it is the struggle of wild boar

338 with its biotope (Naguib 2006). Our study supports this hypothesis. Further, we distinguished

339 between basic animal behaviour serving the survival of the individuals and the sounder, and

340 comforting behaviour aimed at the well-being of the individuals.

341 Our data supports, that wild boar use different behavioural elements for reaching different food

342 resources. For example, rooting and pawing serve for the exposing of food sources in the ground

343 (GÖT and BAT 2003). Wild boar can distinguish between food places of different quality and

344 relocate them which saves energy and time (Held et al. 2005). Moreover, sows suckle their

345 offspring and therefore invest in the breeding and survival of their offspring (Vetter et al. 2016).

346 Our results show, that the functions of different behavioural elements are closely related. Wild

347 boar, for example, have a very developed sense of smell (Graves 1984; Mayer 2009). The

348 olfactory behaviour serves for foraging and avoidance of predators (sniffing and winding) as

349 well as for intraspecific communication by defecating and urinating. Also rubbing, nibbling as

350 well as nose-to-nose contact and nose-to-body contact serve for intraspecific communication.

351 Vigilance behaviour (pausing) seemed to be a reaction to the camera traps. Our results show that

352 wild boar, compared to other animals, hardly react to camera traps, but when they react, they do

353 it by eye-contact or pausing (Amelin 2014). Wild boar are reclusive animals (Gundlach 1968;

354 Beuerle 1975; Altmann 1989). Vigilance behaviour is used by wild boar to avoid predation (e.g. 
355 by humans or wolves), for example when a sow guards a glade before other sows and young 356 animals follow her. When pausing or laying down, the movement is abruptly stopped which 357 otherwise would produce a noise, which predators could hear. Moreover, young boar are very 358 camouflaged while laying down due to their striped pattern (Briedermann 2009). The animals 359 also use this moment to scan their environment multisensory (Quenette and Desportes 1992). If 360 the boar do not find the source of the noise or sense disturbing them, it could be that they react 361 with flight.

362 The behavioural category comfort behaviour mostly serves for two functions, personal hygiene 363 behaviour and resting behaviour. Looking at the personal hygiene behaviour, wild boar use 364 wallowing for thermoregulation because they are not able to sweat and a mud layer also keeps 365 stinging insects away (Meynhardt 1982; GÖT and BAT 2003; Briedermann 2009). According to 366 another study, wild boar immobilise stinging insects with help of the mud and afterwards remove 367 them by rubbing and similar behaviour (Mayer 2009). Rubbing is also caused by hair change in 368 spring-time (Briedermann 1971). Thus, comfort behaviour serves for the well-being of the 369 animals in general (GÖT and BAT 2003). In contrast to the results of previous studies, where 370 stretching was always observed after resting behaviour (Briedermann 2009), in our study 371 stretching also could be seen three times mostly after rubbing and before shaking.

372 The social interactions of wild boar have different functions. Nose-to-nose contact and nose-to373 body contact serve as intraspecific communication (see above). This is important for the mother374 infant-relationship (Gundlach 1968; Meynhardt 1982), and for sexual behaviour (e.g. courtship 375 of boars, boar fights), which serves for reproduction. It is said that each behaviour is noticed by 376 group members and has social consequences (Stolba and Wood-Gush 1989), allowing them to 377 learn from each other (Schneider 1980; Briedermann 2009; Morelle et al. 2014). Young boar 
378 train from an early age on fighting and copulation in a playful manner (Gundlach 1968;

379 Meynhardt 1982; GÖT and BAT 2003), which they use later during the mating season for boar

380 fights and mating. Wild boar also compete for food, however, they have a stable food hierarchy

381 (Beuerle 1975; GÖT and BAT 2003; Saebel 2007) to avoid unnecessary competition and to save

382 energy.

383 Resting behaviour like sleeping was not observed in this study. Wild boar rest at their daytime 384 resting sites (Gundlach 1968; Meynhardt 1982) which were never placed in front of any of the 60 385 camera traps. As wild boar prefer dense vegetation for their resting places (Allwin et al. 2016) it 386 is statistically unlikely to catch such places randomly, since the camera traps need some open 387 space to work correctly (cf. data collection). Again, we also do not know any resting place of 388 wild boar in our study area, consequently it was not possible to place one of the 10 additional 389 camera traps at their daytime resting sites. To analyse this behaviour in following studies we suggest permanently placing recording video systems at preferred resting sites which should be determined before with help of telemetry (Lampe 2004; Sándor et al. 2014). Since our results stem only from videos in forest habitats, a lack of observations from open areas may explain lacks of activity maxima in the hour of 18:00 o'clock and between 01:00 and 02:59 o'clock, because at that time wild boar were probably on greens, fields or at baiting stations (in surroundings of private hunting grounds) for foraging. Another possibility is that the animals had 396 an activity break between 01:00 and 02:59 o'clock in which time resting behaviour could have

397 been observable. It has already been suggested that free roaming wild boar have a rest period in 398 the second half of the night (Briedermann 1971), diurnal wild boar around midday respectively 399 (Allwin et al. 2016). 
400 The expansion of humans results in wild boar's habitat reduction. Due to the lack of natural

401 predators in many places and increasing food supply, the wild boar population numbers are

402 constantly increasing (Massei et al. 2014) and consequently it comes to their invasion into urban

403 areas (Kotulski and König 2008; Toger et al. 2018; Conejero et al. 2019). This leads to many

404 conflicts between wild boar and humans. As wild boar are very adaptable, one method alone is

405 not sufficient to reduce the animal's number. In addition to the procedures already known (cf.

406 West et al. 2009, Tack 2018), the results of this work show further possibilities, such as hunting

407 the animals during their activity times at night with night vision devices at known social

408 locations, and avoiding additional foraging resources (e.g. access to food waste) during their

409 foraging activity times. In general, knowledge of habitat preferences and behavioural needs are

410 useful for habitat management. Keeping wild boar in their "comfort habitats" could reduce

411 human wild boar conflicts such as crop and rooting damages, if enough preferred habitats are

412 available. Additionally, the public needs to be better informed about the effects of increasing

413 wild boar population numbers, as there is, for example, a growing negative public opinion

414 towards hunting (Tack 2018). Consequently, wild boar behaviours drive the human perception of

415 the wildlife-human conflict and thus determine the way of implementing wildlife population

416 management measures. But we are also responsible for the living conditions of wild boar in

417 captivity such as zoos and domestic pigs in factory farming. Enclosure design and activities can

418 significantly improve animal welfare. Our results can be used as a model to show which habitat

419 requirements an enclosure should fulfil (e.g. coniferous woods for rubbing, wallows, retreats), at

420 what times and in what form food should be given (rooting possibilities), and when the animals

421 should be allowed to rest. These are only a few examples. 
422 The behavioural elements salt ingestion, feeding attempt, getting frightened, stretching, nibbling,

423 wallowing, chasing away, snout knock, and copulation attempt could only be observed at the

424 non-random points and could therefore not be statistically analysed. On the other hand the

425 behavioural elements defecating, urinating, guarding, suckling, scratching one's bottom and

426 rolling only occurred at the random points. Many important behavioural elements like wallowing

427 and rubbing occur only in certain places and are not necessarily detected by a random

428 distribution. Therefore, it is even more important to observe not only random places but also

429 known whereabouts of the wild boar in order to uncover the entire behavioural repertoire of the

430 species and to describe their needs. In order to increase the chance for documentation of rarely

431 observed behaviours, further studies should be conducted in which more camera traps are placed

432 comparing different localities and populations, as several behaviours could not be observed in

433 this study due to the biotope (habitat) of animals. Furthermore, mating and mating-related fights

434 of males take place from November till January (Meynhardt 1982; Altmann 1989; Briedermann

435 2009) which is beyond the observation season. The season also has an influence on biotope

436 choice (Keuling et al. 2009). Thus in future studies, it would be advisable to observe wild boar

437 for at least one year via camera traps to get a whole impression of their spatiotemporal

438 behaviour. This year long observation would also account for possible weather influences on the

439 activity and habitat choice of wild boar (Saebel 2007; Briedermann 2009; Allwin et al. 2016).

440 Sound recordings could, hence, be taken when looking at courtship interactions to record

441 communication behaviour and to eliminate the influence of the data collection via camera traps.

442 Currently, the numbers of wolves are rising across Europe (Randi 2011; Arbieu et al. 2019) and

443 hence, likely influence the behaviour of wild boar, like they do in other species, e.g. roe deer

444 (Bongi et al. 2008) and alpine ibex (Grignolio et al. 2019). This study can serve as a baseline 
445 study to record behavioural changes of wild boar in areas in which apex predators are recurring

446 and increasing. To see if the spatiotemporal behaviour changes, future studies could compare

447 different study areas (including or excluding predators, hunting and other human impact,

448 different habitats, different seasons during some consecutive total years).

\section{Conclusion}

452 The behaviour of wild boar is a result of the interaction of intrinsic and extrinsic factors - and thus, it is the struggle of wild boar with its biotope. Essential behavioural categories like foraging

454 behaviour, locomotion and vigilance behaviour occurred more frequently than behaviour "just" 455 serving for the well-being of wild boar. Accordingly, the activity maxima of these three 456 behavioural categories could be observed at the same time and predominantly in the first half of 457 the night. To suggest some management measures, during this time the hunting pressure should 458 be enlarged and the supply of human food resources should be avoided. Additionally, the results 459 of this study are an important contribution towards wild boar welfare in enclosures, showing their basic requirements for habitats to fulfil their natural behavioural repertoire. Video traps are

461 a good method to observe the behaviour of animals under natural conditions. Although video 462 traps are not always reliably triggered by wild boar, using a high number of them gives an 463 effective alternative compared to telemetry which would require wild boar disturbing direct 464 observations. In further studies it would be advisable to observe wild boar year round with 465 additional sound recordings to get an overall impression of the wild boar behavioural repertoire 466 and to increase the chance of detecting rare behaviours as well as behavioural changes due to 467 human or recurring large predator impacts. 


\section{Acknowledgements}

471 We would like to thank all people, who helped within our research: all hunters and employees of

472 the Forestry Office of Oerrel and the Big Game Association "Hochwildring Süsing", all

473 colleagues and students for help during field work and analyses, and Katrin Ronnenberg for

474 statistical support. We are grateful to Taren Heintz and Marie Sange for revising the English and

475 to Maraja Riechers for reviewing an early draft of the manuscript.

476

477

\section{References}

Allwin B, Swaminathan R, Mohanraj A, Suhas GN, Vedaminckam S, Gopal S, Kumar M (2016) The Wild Pig (Sus scrofa) Behavior - A Retrospective Study. Journal of Veterinary Science Technology 7. doi: 10.4172/2157-7579.1000333.

Altmann D (1989) Sozialverhalten und Revierverteidigung in Beziehung zur Tageszeit beim Wildschwein, Sus scrofa L. Beiträge zur Jagd- und Wildforschung 16:202-211.

Altmann J (1974) Observational study of behavior: Sampling methods. Behaviour 69:227-267.

Amelin M (2014) Analyse von Auslösefehlern bei Wildkameras mittels Videoüberwachung und Reaktion von Wildtieren auf Infrarotblitze. B. Sc. Thesis, Gottfried Wilhelm Leibniz Universität Hannover.

Arbieu U, Mehring M, Bunnefeld N, Kaczensky P, Reinhardt I, Ansorge H, Böhning-Gaese K, Glikman JA, Klut G, Nowak C, Müller T (2019) Attitudes towards returning wolves (Canis lupus) in Germany: Exposure, information sources and trust matter. Biological Conservation 234:202-210. doi: 10.1016/j.biocon.2019.03.027.

Bengsen AJ, Leung LK-P, Lapidge SJ, Gordon IJ (2011) Using a general index approach to analyze camera-trap abundance indices. The Journal of Wildlife Management 75:1222-1227. doi: 10.1002/jwmg.132.

Berger K (2006) Winterhabitatnutzung dreier subadulter, männlicher Wildschweine (Sus scrofa L.) im Pfälzerwald. D. Thesis, Albert-Ludwigs-Universität Freiburg. 
496

497

498

499

500

501

502

503

504

505

506

507

508

509

510

511

512

513

514

515

516

517

518

519

520

521

522

523

524

525

526

527

528

529

Bertolotto E (2010) Behavioural ecology of wild boar (Sus scrofa) in an Apennine environment. Ph. D. Thesis, University of Sassari, Italy.

Beuerle W (1975) Freilanduntersuchungen zum Kampf- und Sexualverhalten des europäischen Wildschweines (Sus scrofa L.). Zeitschrift für Tierpsychologie 39:211-258.

Bjornstad ON, Cai J (2020) Ncf: Spatial Covariance Functions. R Package Version 1.2-9.

Bongi P, Ciuti S, Grignolio S, Del Frate M, Simi S, Gandelli D, Apollonio M (2008) Anti-predator behaviour, space use and habitat selection in female roe deer during the fawning season in a wolf area. Journal of Zoology. doi: 10.1111/j.1469-7998.2008.00481.x.

Briedermann L (2009) Schwarzwild: Neuausgabe bearbeitet von Burkhard Stöcker. Kosmos, Stuttgart.

Briedermann L (1971) Ermittlungen zur Aktivitätsperiodik des Mitteleuropäischen Wildschweines (Sus s. srofa L.). Der Zoologische Garten N.F., Leipzig 40:302-327.

Broom DM, Sena H, Moynihan KL (2009) Pigs learn what a mirror image represents and use it to obtain information. Animal Behaviour 78:1037-1041. doi: 10.1016/j.anbehav.2009.07.027.

Cagnacci F, Boitani L, Powell RA, Boyce MS (2010) Animal ecology meets GPS-based radiotelemetry: a perfect storm of opportunities and challenges. Philosophical Transactions of the Royal Society B 365:2157-2162. doi: 10.1098/rstb.2010.0107.

Cahill S, Llimona F, Gràcia J (2003) Spacing and nocturnal activity of wild boar Sus scrofa in a Mediterranean metropolitan park. Wildlife Biology 9:3-13.

Choquenot D, McIlroy J, Korn T (1996) Managing vertebrate pests: Feral pigs. Bureau of Resource Sciences, Australian Government Publishing Service, Canberra.

Conejero C, Castillo-Contreras R, González-Crespo C, Serrano E, Mentaberre G, Lavín S, López-Olvera JR (2019) Past experiences drive citizen perception of wild boar in urban areas. Mammalian Biology 96:68-72. doi: 10.1016/j.mambio.2019.04.002.

Dormann CF, Kühn I (2009) Angewandte Statistik für die biologischen Wissenschaften, 2nd edn. Helmholtz Zentrum für Umweltforschung-UFZ.

Focardi S, Morimando F, Capriotti S, Ahmed A, Genov P (2015) Cooperation improves the access of wild boars (Sus scrofa) to food sources. Behavioural Processes 121:80-86. doi: 10.1016/j.beproc.2015.10.019.

Gaillard J-M, Hebblewhite M, Loison A, Fuller M, Powell R, Basille M, Van Moorter B (2010) Habitatperformance relationships: finding the right metric at a given spatial scale. Philosophical Transactions of the Royal Society B 365:2255-2265. doi: 10.1098/rstb.2010.0085.

Gatesy J (2009) Whales and even-toed ungulates (Cetartiodactyla). In: Hedges SB, Kumar S (eds) The timetree of life. Oxford University Press, pp 511-515.

Geissmann T (2002) Verhaltensbiologische Forschungsmethoden. Eine Einführung. Schüling Verlag, 
530

531

532

533

534

535

536

537

538

539

540

541

542

543

544

545

546

547

548

549

550

551

552

553

554

555

556

557

558

559

560

561

562

563

Münster.

Gesellschaft für Ökologische Tierhaltung e.V. (GÖT), Verein Beratung artgerechter Tierhaltung e.V. (BAT) (2003) Verhalten, artgerechte Haltungssysteme und Stalleinrichtungen für Rind, Schwein und Huhn. Schlussbericht (Teil II) an das Bundesministerium für Ernährung, Landwirtschaft und Verbraucherschutz im Rahmen des Bundesprogramms Ökologischer Landbau 30-32.

Graves HB (1984) Behavior and ecology of wild and feral swine (Sus Scrofa). Journal of Animal Science $58: 482-492$.

Grignolio S, Brivio F, Sica N, Apollonio M (2019) Sexual differences in the behavioural response to a variation in predation risk. Ethology 125:603-612. doi: 10.1111/eth.12887.

Gundlach H (1968) Brutfürsorge, Brutpflege, Verhaltensontogenese und Tagesperiodik beim Europäischen Wildschwein (Sus scrofa L.). Zeitschrift für Tierpsychologie 25:955-995.

Held S, Baumgartner J, KilBride A, Byrne RW, Mendl M (2005) Foraging behaviour in domestic pigs (Sus scrofa): remembering and prioritizing food sites of different value. Animal Cognition 8:114121. doi: 10.1007/s10071-004-0242-y.

Hofmeester TR, Rowcliffe JM, Jansen PA (2017) A simple method for estimating the effective detection distance of camera traps. Remote Sensing in Ecology and Conservation 3:81-89. doi: $10.1002 /$ rse2.25.

Hothorn T, Bretz F, Westfall P (2014) Mmultcomp: Simultaneous Inference in General Parametric Models. R Package Version 1.3-7.

Kappeler P (2009) Verhaltensbiologie, 2nd edn. Springer, Berlin, Heidelberg.

Keuling O, Herbst C, Daim A, Siebert U (2013) Schwarzwildbewirtschaftung im Hochwildring Süsing. Jahresbericht 2012 an das Niedersächsische Ministerium für Ernährung, Landwirtschaft, Verbraucherschutz und Landesentwicklung. Stiftung Tierärztliche Hochschule Hannover.

Keuling O, Podgórski T, Monaco A, Melletti M, Merta D, Albrycht M, Genov PV, Gethöffer F, Vetter SG, Jori F, Scalera R, Gongora J (2018) Eurasian Wild Boar Sus scrofa (Linnaeus, 1758). In: Melletti M, Meijaard E (eds) Ecology, Conservation and Management of Wild Pigs and Peccaries. Cambridge University Press, Cambridge, pp 202-233.

Keuling O, Stier N (2009) Schwarzwild - Untersuchungen zu Raum- und Habitatnutzung des Schwarzwildes (Sus scrofa L. 1758) in Südwest-Mecklenburg unter besonderer Berücksichtigung des Bejagungseinflusses und der Rolle älterer Stücke in den Rotten. Abschlussbericht 2002-2006 an die Oberste Jagdbehörde im Ministerium für Landwirtschaft, Umwelt und Verbraucherschutz Mecklenburg-Vorpommern und die Stiftung „Wald und Wild Mecklenburg-Vorpommern“. Technische Universität Dresden.

Keuling O, Stier N, Roth M (2009) Commuting, shifting or remaining? Different spatial utilisation 
564

565

566

567

568

569

570

571

572

573

574

575

576

577

578

579

580

581

582

583

584

585

586

587

588

589

590

591

592

593

594

595

596

597

patterns of wild boar Sus scrofa L. in forest and field crops during summer. Mammalian Biology 74:145-152. doi: 10.1016/j.mambio.2008.05.007.

Kotulski Y, König A (2008) Conflicts, crises and challenges: wild boar in the Berlin City - a social empirical and statistical survey. Natura Croatica 17:233-246.

Kovács V, Újváry D, Szemethy L (2017) Availability of camera trapping for behavioural analysis: An example with wild boar (Sus scrofa). Applied Animal Behaviour Science 195:112-114. doi: 10.1016/j.applanim.2017.05.019.

Lampe T (2004) Wie Sau sich bettet - über die Wahl der Schlafplätze bei Wildschweinen (Sus scrofa). D. Thesis, Universität Bielefeld.

Lemel J, Truvé J, Söderberg B (2003) Variation in ranging and activity behaviour of European wild boar Sus scrofa in Sweden. Wildlife Biology 9:29-36.

Lowe S, Browne M, Boudjelas S, De Poorter M (2000) 100 of the worls's worst invasive alien species: A selection from the Global Invasive Species Database. The Invasive Species Specialist Group (ISSG) a specialist group of the Species Survival Commission (SSC) of the World Conservation Union (IUCN).

Maselli V, Rippa D, Russo G, Ligrone R, Soppelsa O, D'Aniello B, Raia P, Fulgione D (2014) Wild boars' social structure in the Mediterranean habitat. Italian Journal of Zoology 81:610-617. doi: 10.1080/11250003.2014.953220.

Massei G, Kindberg J, Licoppe A, Gačić D, Šprem N, Kamler J, Baubet,E, Hohmann U, Monaco A, Ozoliņš J, Cellina S, Podgórski T, Fonseca C, Markov N, Pokorny B, Rosell C, Náhlik A (2014) Wild boar populations up, numbers of hunters down? A review of trends and implications for Europe. Pest Management Science 71. doi: 10.1002/ps.3965.

Mayer JJ (2009) Biology of wild pigs: Wild pig behavior. In: Mayer JJ, Brisbin ILJ (eds) Wild pigs: Biology, damage, control techniques and management. Savannah River National Laboratory, Aiken, South Carolina, pp 77-104.

Meek P, Ballard G, Fleming P (2012) An introduction to camera trapping for wildlife surveys in Australia. Invasive Animals Cooperative Research Centre, Canberra.

Meynhardt H (1982) Schwarzwild-Report: Mein Leben unter Wildschweinen, 7th edn. NeumannNeudamm, Leipzig, Radebeul.

Morelle K, Podgórski T, Prévot C, Keuling O, Lehaire F, Lejeune P (2014) Towards understanding wild boar Sus scrofa movement: a synthetic movement ecology approach. Mammal Review. doi: 10.1111/mam.12028.

Naguib M (2006) Methoden der Verhaltensbiologie. Springer, Berlin, Heidelberg.

NIST/SEMATECH (2013) E-Handbook of Statistical Methods: 7.4.7.1. Tukey's method. In: US 
598 Department of Commerce. http://www.itl.nist.gov/div898/handbook/prc/section4/prc471.htm.

599 Owen-Smith N, Fryxell JM, Merrill EH (2010) Foraging theory upscaled: the behavioural ecology of 600 herbivore movement. Philosophical Transactions of the Royal Society B 365:2267-2278. doi: $601 \quad 10.1098 /$ rstb.2010.0095.

602 Passon C, Keuling O, Gräber R, Neubauer D, Brün J (2012) Estimating wild boar (Sus scrofa) density 603 using camera traps and distance sampling. In: 9th International Symposium on Wild Boar and other 604 Suids. Hannover, Germany (02.-06.09.2012).

605 Pinheiro J, Bates D (2014) Nlme: Linear and Nonlinear Mixed Effects Models. R Package Version 3.1$606 \quad 118$.

607 Price SA, Bininda-Emonds ORP, Gittleman JL (2005) A complete phylogeny of the whales, dolphins and 608 even-toed hoofed mammals (Cetartiodactyla). Biological Reviews 80:445-473.

609 doi:10.1017/S1464793105006743.

610 Probst C, Globig A, Knoll B, Conraths,FJ, Depner,K (2017) Behaviour of free ranging wild boar towards 611 their dead fellows: potential implications for the transmission of African swine fever. Royal Society 612 Open Science 4. doi: 10.6084/m9.figshare.c.3780125.

613 Quenette PY, Desportes JP (1992) Temporal and sequential structures of vigilance behavior of wild boars 614 (Sus scrofa). Journal of Mammalogy 73:535-540.

615 R Core Team (2014) R: A language and environment for statistical computing. R Foundation for 616 Statistical Computing, Vienna, Austria. http://www.R-project.org/.

617 R Core Team (2020) R: A language and environment for statistical computing. R Foundation for 618 Statistical Computing, Vienna, Austria. http://www.R-project.org/.

619 Randi E (2011) Genetics and conservation of wolves Canis lupus in Europe. Mammal Review 41:99-111. 620 doi: $10.1111 /$ j.1365-2907.2010.00176.x.

621 Rovero F, Tobler M, Sanderson J (2010) Camera trapping for inventorying terrestrial vertebrates. In:

622 Eymann J, Degreef J, Häuser C, Monje JC, Samyn Y, van den Spiegel D (eds) Manual on field 623 recording techniques and protocols for All Taxa Biodiversity Inventories and Monitoring. The 624 Belgian National Focal Point to the Global Taxonomy Initiative, pp 100-128.

625 Rovero F, Zimmermann F, Berzi D, Meek P (2013) “Which camera trap type and how many do I need?" 626 A review of camera features and study designs for a range of wildlife research applications. Hystrix, 627 the Italian Journal of Mammalogy 24:148-156. doi: 10.4404/hystrix-24.2-8789.

628 Rowcliffe JM, Carbone C, Jansen PA, Kays R, Kranstauber B (2011) Quantifying the sensitivity of 629 630 camera traps: An adapted distance sampling approach. Methods in Ecology and Evolution 2:464476.

631 Rowcliffe JM, Field J, Turvey ST, Carbone C (2008) Estimating animal density using camera traps 
632

633

634

635

636

637

638

639

640

641

642

643

644

645

646

647

648

649

650

651

652

653

654

655

656

657

658

659

without the need for individual recognition. Journal of Applied Ecology 45:1228-1236.

Rowcliffe JM, Jansen PA, Kays R, Kranstauber B, Carbone C (2016) Wildlife speed cameras: measuring animal travel speed and day range using camera traps. Remote Sensing in Ecology and Conservation 2:84-94. doi: 10.1002/rse2.17.

Saebel J (2007) Verhaltensbeobachtungen am Schwarzwild (Sus scrofa L.) durch Videoüberwachung und Radiotelemetrie. D. Thesis, Technische Universität Dresden.

Sándor G, Tari T, Heffenträger G, Pócza G, Náhlik A (2014) Daytime habitat use of wild boar. [Abstract] In: 10th International Symposium on Wild Boar and other Suids. Velenje, Slovenia (01.05.09.2014).

SAS Institute Inc. (2011) SAS/STAT ${ }^{\circledR} 9.3$ User's Guide. SAS Institute Inc., Cary, North Carolina.

Schneider E (1980) Markierung und Inbesitznahme von Futter, Nachahmung und Lernen beim europäischen Wildschein (Sus scrofa L.). Zeitschrift für Jagdwissenschaft 26:126-132.

Sommer V, Lowe A, Dietrich T (2016) Not eating like a pig: European wild boar wash their food. Animal Cognition 19:245-249. doi: 10.1007/s10071-015-0903-z.

Stolba A, Wood-Gush DGM (1989) The behaviour of pigs in a semi-natural environment. Animal Production 48:419-425. doi: 10.1017/S0003356100040411.

Tack J (2018) Wild Boar (Sus scrofa) populations in Europe: A scientific review of population trends and implications for management. European Landowners' Organization, Brussels.

Toger M, Benenson I, Wang Y, Czamanski D, Malkinson D (2018) Pigs in space: an agent-based model of wild boar (Sus scrofa) movement into cities. Landscape and Urban Planning 173:70-80. doi: 10.1016/j.landurbplan.2018.01.006.

Vetter SG, Brandstätter C, Macheiner M, Suchentrunk F, Gerritsmann H, Bieber C (2016) Shy is sometimes better: personality and juvenile body mass affect adult reproductive success in wild boars, Sus scrofa. Animal Behaviour 115:193-205. doi: 10.1016/j.anbehav.2016.03.026.

West BC, Cooper AL, Armstrong JB (2009) Managing wild pigs: A technical guide. Human-Wildlife Interactions Monograph 1:1-55.

Wood S (2014) Mgcv: Mixed GAM Computation Vehicle with GCV/AIC/REML smoothness estimation. R Package Version 1.8-3. 
Figure 1

Occurrence of the behavioural categories at the random points.

The mean number of videos clips per day is shown for the six behavioural categories $(L=$ locomotion, $\mathrm{OB}=$ olfactory behaviour, $\mathrm{VB}=$ vigilance behaviour, $\mathrm{FB}=$ foraging behaviour, $\mathrm{CB}$ = comfort behaviour, $\mathrm{SI}=$ social interaction) as box plots with minimum, lower quantile, median, upper quantile, maximum and outlier, observed at the random points $(\mathrm{N}=1407$; 645 videos clips).

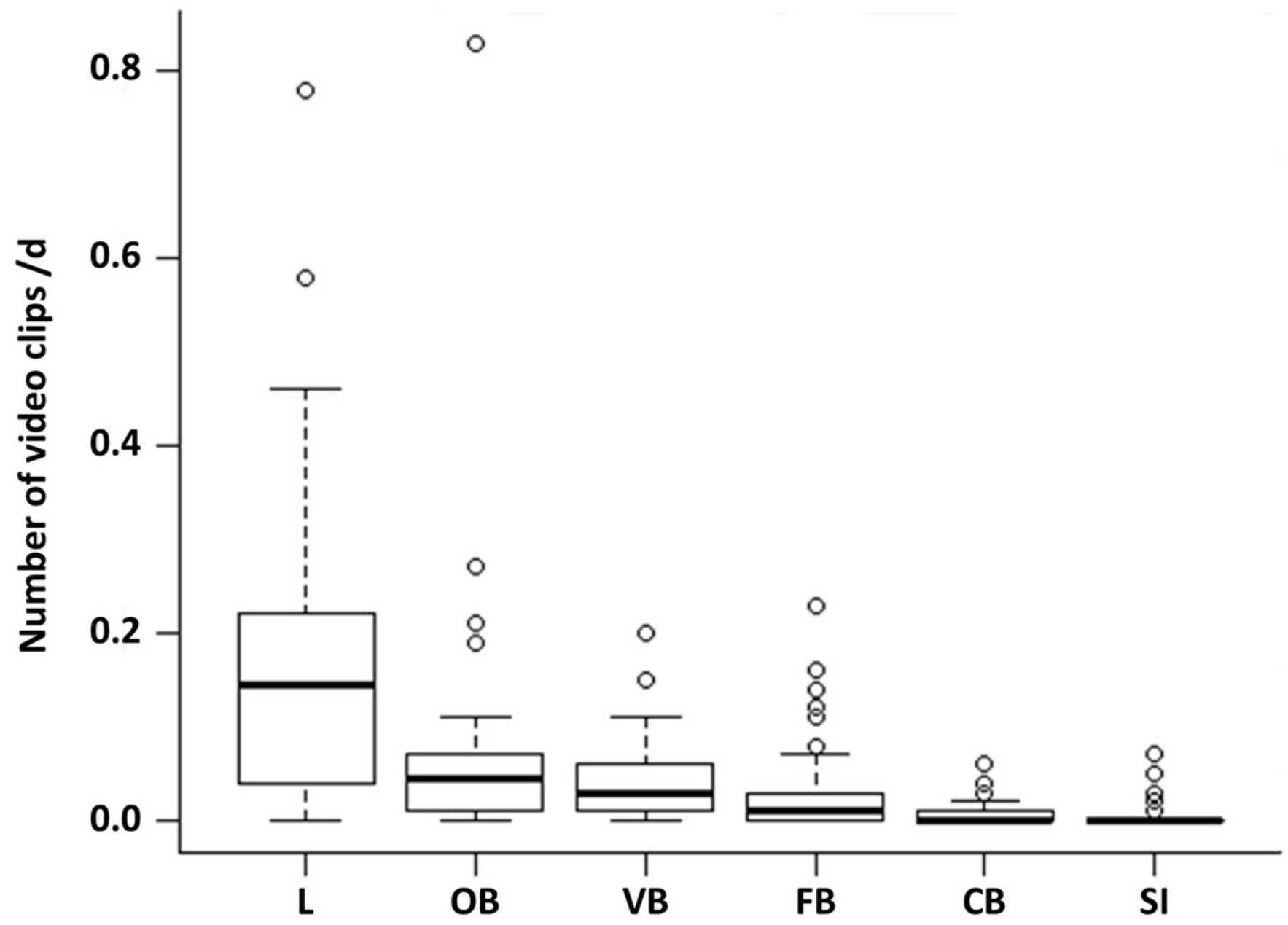


Figure 2

Activity maxima per behavioural category.

A visual summary of the results is shown for all seven behavioural categories with maxima (= two frequency peaks), secondary (= one frequency peak) and low maxima (a half frequency peak, respectively a tenth frequency peak for sexual behaviour) (with e.g. 00:00 = 00:00-00:59) $(\mathrm{N}=1227)$.

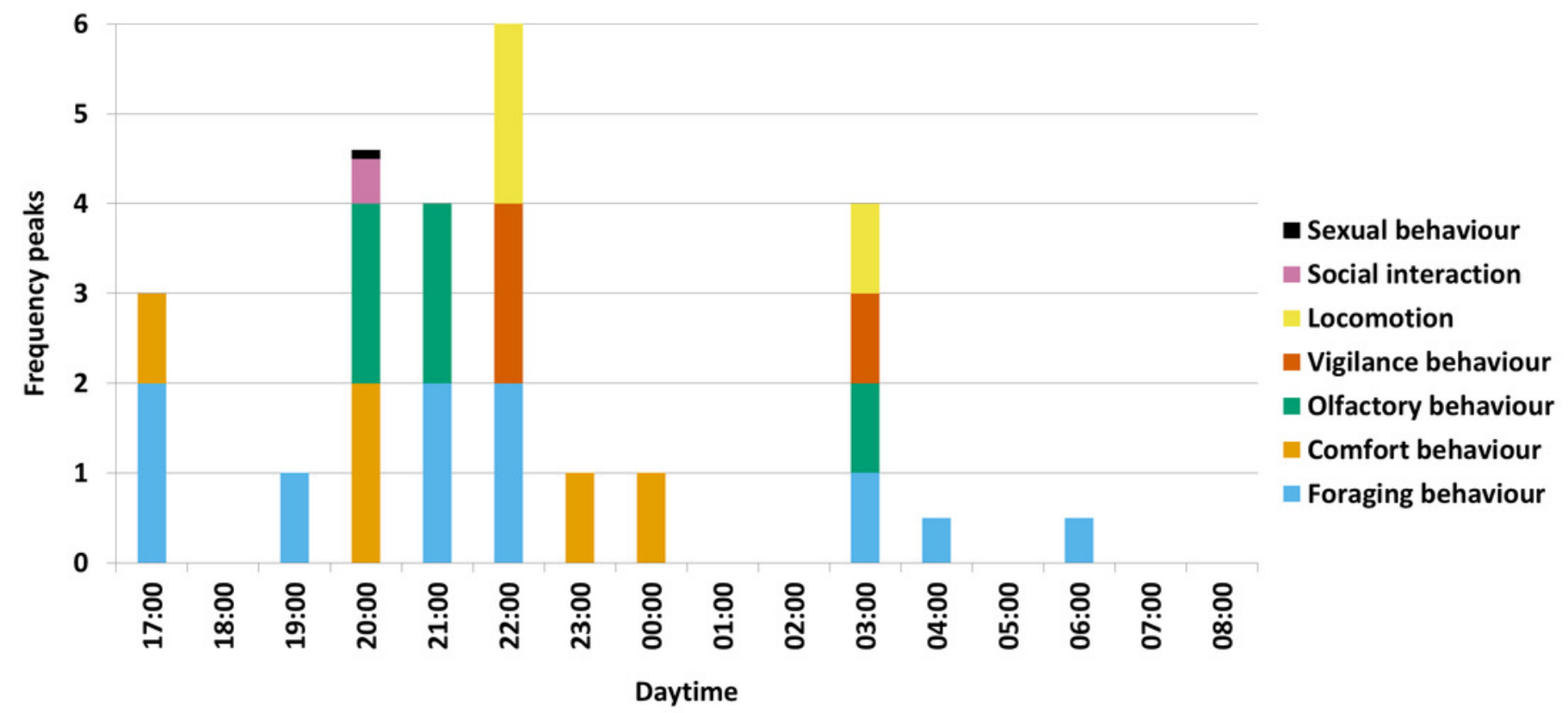




\section{Table 1 (on next page)}

Ethogram for the classification and definition of the behavioural elements of the observed wild boar. 
1 Table 1. Ethogram for the classification and definition of the behavioural elements of the observed wild boar.

2

\begin{tabular}{|c|c|}
\hline Context & Definition \\
\hline \multicolumn{2}{|l|}{ Locomotion (L) } \\
\hline Walking & $\begin{array}{l}\text { Slow movement (pace), every leg is moved at least one step (also backwards } \\
\text { possible). }\end{array}$ \\
\hline Running & Fast movement (trot and faster). \\
\hline Jumping & Jump over an obstacle or ditch. \\
\hline Flight & Abrupt escape from recent whereabouts (optionally just a few steps). \\
\hline \multicolumn{2}{|c|}{ Olfactory behaviour (OB) } \\
\hline Sniffing & Sniffing on the ground or between plants of the ground and herb layer. \\
\hline Winding & Sniffing in the air or at something (e.g. rubbing tree, camera). \\
\hline Defecating & Emptying of the gut. \\
\hline Urinating & Total drain of the bladder. \\
\hline \multicolumn{2}{|c|}{ Vigilance behaviour (VB) } \\
\hline Getting frightened & Short wince of the whole body. \\
\hline Pausing & Freeze of motion with alert view and potential additional head lift and look about. \\
\hline Laying down & Young boar presses its body abrupt even on the ground. \\
\hline Guarding & Alert milling around, with lifted head and tail, obvious tense posture. \\
\hline \multicolumn{2}{|c|}{ Foraging behaviour (FB) } \\
\hline Pawing & Pawing in the ground (e.g. soil, leaves) with a foreleg. \\
\hline Rooting & $\begin{array}{l}\text { Rooting in the ground (e.g. soil, leaves) with the snout, also with brushing big } \\
\text { branches aside. }\end{array}$ \\
\hline Salt ingestion & Ingestion of salt at a salt lick by licking, nibbling. \\
\hline Sucking attempt & Young boar attempt to suck on the sow's teats or briefly suck at the standing sow. \\
\hline Suckling & Young boar are suckled by the lying sow. \\
\hline Chewing & Uniform opening and closing of the mouth after foraging (feeding not visible). \\
\hline Feeding attempt & Young boar takes soil/stone into its mouth. \\
\hline Feeding & Ingestion of food with the mouth and chewing afterwards. \\
\hline Drinking & Ingestion of water with the mouth. \\
\hline
\end{tabular}

\section{Comfort behaviour (CB) - personal hygiene behaviour}

Stretching

Shaking

Rubbing

Nibbling

Scratching
Increasing the distance of the hind legs to the forelegs and slightly spreading of the hind legs while simultaneously scuttling with the forelegs.

Moving its body strongly, briefly and fast back and forth while standing.

Rubbing one's body against a tree or another wild boar.

Nibbling/rubbing of the open mouth against the rubbing tree.

Scratching one's body with the hind legs. 
Scratching one's bottom Rubbing one's bottom against the ground while sitting.

Rolling

Rubbing one's body against the ground.

Wallowing

Laying down (and optionally wallowing) in muddy water.

\section{Social interaction (SI)}

Active socio negative interaction

Threating

Keeping another wild boar at distance by threating behaviour.

Pushing away softly

Pushing another wild boar softly away with the head, the side of the body or the bottom.

Chasing away A wild boar runs after another wild boar, which departs itself afterwards.

Snout knock

A wild boar knocks its head bottom-up in the direction of another wild boar

(with/without touching).

Passive socio negative interaction

Retreating

A wild boar increases the distance to another wild boar, which emitted socio negative behaviour before.

Socio positive interaction

Nose-to-nose contact

Sniffing at or touching the snout region (being sent of one or both wild boar, also at distance).

Nose-to-body contact A wild boar sniffs at or touches another wild boar with the snout at its body or legs.

Playing Playful behaviour against other wild boar (e.g. exercise fights, apparent copulation attempt).

Sexual behaviour (SB)

Copulation attempt

A wild boar climbs the bottom of another wild boar.

3 


\section{Table 2 (on next page)}

Results of the LMM and LSMEAN.

Comparison of the occurrence of each behavioural category with each other. The estimate and $p$-value of each pairwise comparison of means with Tukey adjustment is shown. 
1 Table 2. Results of the LMM and LSMEAN. Comparison of the occurrence of each behavioural category with 2 each other. The estimate and p-value of each pair wise comparison of means with Tukey adjustment is shown.

3

\begin{tabular}{|c|c|c|c|c|}
\hline \multicolumn{3}{|c|}{ Pair wise comparison } & \multirow{2}{*}{$\begin{array}{c}\text { Estimate } \\
0.084\end{array}$} & \multirow{2}{*}{$\begin{array}{r}\text { p-value } \\
<0.001 * * *\end{array}$} \\
\hline Locomotion & - & Olfactory behaviour & & \\
\hline Locomotion & - & Vigilance behaviour & 0.106 & $<0.001 * * *$ \\
\hline Locomotion & - & Foraging behaviour & 0.120 & $<0.001 * * *$ \\
\hline Locomotion & - & Comfort behaviour & 0.141 & $<0.001 * * *$ \\
\hline Locomotion & - & Social interaction & 0.141 & $<0.001 * * *$ \\
\hline Olfactory behaviour & - & Vigilance behaviour & 0.023 & $>0.05$ \\
\hline Olfactory behaviour & - & Foraging behaviour & 0.037 & $0.007 * *$ \\
\hline Olfactory behaviour & - & Comfort behaviour & 0.057 & $<0.001 * * *$ \\
\hline Olfactory behaviour & - & Social interaction & 0.057 & $<0.001 * * *$ \\
\hline Vigilance behaviour & - & Foraging behaviour & 0.014 & $>0.05$ \\
\hline Vigilance behaviour & - & Comfort behaviour & 0.034 & $0.014 *$ \\
\hline Vigilance behaviour & - & Social interaction & 0.035 & $0.012 *$ \\
\hline Foraging behaviour & - & Comfort behaviour & 0.020 & $>0.05$ \\
\hline Foraging behaviour & - & Social interaction & 0.021 & $>0.05$ \\
\hline Comfort behaviour & - & Social interaction & $<0.001$ & $>0.05$ \\
\hline
\end{tabular}

4 